\author{
Julio Pascual \\ Yasmina el Berdei \\ José C. Gómez-Sánchez
}

\section{How many migraine patients need prolonged (>1 year) preventive treatment? Experience with topiramate}

Received: 5 October 2006

Accepted in revised form: 2 November 2006

Published online: 15 January 2007
J. Pascual (凶) • Y. el Berdei

J.C. Gómez-Sánchez

Service of Neurology,

University Hospital,

Paseo de San Vicente 58-132,

37007 Salamanca, Spain

e-mail: juliopascual@telefonica.net

Tel.: +34-9-23291334

Fax: +34-9-23291333

\begin{abstract}
The usual recommended duration of preventive treatment for migraine is $3-6$ months. Our aim was to explore how many patients attending a specialised clinic need prolonged preventive treatment for longer than one year. Eighty consecutive migraine patients who received preventive treatment with topiramate for 3 months with good response and tolerability were included in this observational study. All patients continued on topiramate until they had completed 6 months, when this drug was stopped. Topiramate was reintroduced if there was a worsening. Topiramate was kept for 6 more months and then discontinued again. Those patients whose headaches became worse after this second withdrawal received topiramate again and were
\end{abstract}

followed-up for at least half a year. Headaches did not worsen after the first withdrawal at 6 months in 40 patients $(50 \%)$, while they clearly worsened in the remaining 40 patients. At the end of the first year only two patients out of these 40 (5\%) discontinued topiramate and did not notice an increase in headache frequency after two months. In conclusion, around half of the patients attending a specialised clinic due to frequent headache need preventive treatment for more than one year. Our data suggest that the current practice recommending periods of preventive treatment of 3-6 months should be reconsidered for many patients.

Keywords Migraine $\cdot$ Preventive treatment $\cdot$ Topiramate

\section{Introduction}

Preventive treatment of migraine should be mandatory for patients with frequent headaches. In spite of the fact that at least $25 \%$ of those patients consulting meet criteria for preventive treatment, this option is frequently forgotten, as fewer than $10 \%$ of these patients receive preventatives [1]. In addition, as most trials with preventatives last 3 months and because there are no clear recommendations on the duration of this treatment [2], it not unusual that preventive treatment is withdrawn after only three months. In clinical practice many patients, however, clearly worsen when this treatment is stopped after 3-6 months [2-4]. The newest recommendations, in fact, begin to suggest 6 instead of 3 months for the preventive treatment of migraine.

Our aim was to explore how many migraine patients attending a specialised clinic and treated with topiramate need prolonged treatment for more than one year. 


\section{Patients and methods}

We revised our long-term clinical experience with patients from our headache clinic with a history of International Headache Society [5,6] classified migraine with more than 3 attacks per month who received preventive treatment with topiramate for 3 months with good response (at least $50 \%$ reduction in frequency) and tolerability. Subjects had a history of migraine of at least 1 year. All patients continued on topiramate until they had completed a 6-month treatment period. Topiramate was then slowly (25 mg per week) withdrawn. This drug was reintroduced if there was an worsening after its withdrawal. Topiramate was kept for 6 more months and then withdrawn again. Patients were followed-up for at least 6 additional months. All patients completed at least this follow-up period. Patients were evaluated in our clinic every three months.

Those patients whose headaches became worse after withdrawal at the end of the first year received topiramate again. In these patients we attempted to give up topiramate once a year. A headache diary was provided to each subject.

\section{Results}

A total of 109 patients with more than 3 migraine attacks per month were treated with topiramate in our clinic. Twenty-nine $(26.6 \%)$ either did not tolerate the drug (17 patients, $15,6 \%$ ) or did not obtain a response (12 patients, $11 \%$ ). Eighty (73.4\%) migraine patients (64 women, age range $25-75$ years) with response and good tolerability to topiramate after 3 months remained on topiramate. Fortyeight $(60 \%)$ met criteria for chronic migraine (17 with overuse criteria), 23 (29\%) for migraine without aura and $9(11 \%)$ for migraine with aura. Headaches did not worsen after withdrawal in $40(50 \%)$ patients who were followed for at least 6 months (Fig. 1).

The remaining 40 patients (33 females, 26-75 years) clearly saw their headaches worsened both in frequency and intensity immediately after topiramate withdrawal and received long-term follow-up. Twenty-six (65\% of those 40 patients remaining in the study) met criteria for chronic migraine (11 with overuse), 13 (32.5\%) for migraine without aura and $3(7.5 \%)$ for migraine with aura. Maintenance doses of topiramate at the end of the first year of treatment ranged from 50 to $200 \mathrm{mg}$ /day (mean 91 $\mathrm{mg}$ /day). In these patients, the number of days with migraine headache per month as compared to the month prior to treatment decreased from 19.9 to $7.7(<65 \%)$, with a total of 16 patients $(40 \%)$ having an excellent $(>75 \%$ reduction in headache days) response. Fourteen $(35 \%)$ experienced during the first year of treatment a total of 16 adverse events: 7 showed cognitive symptoms, 5 distal paraesthesias, 3 digestive symptoms and 1 asthenia. Body weight did not change in 18 patients, increased $(5 \mathrm{~kg})$ in one case and decreased in the remaining 21 (range 2-17 $\mathrm{kg}$, mean $6.2 \mathrm{~kg}$ ).

At the end of the first year only two patients (5\%) discontinued topiramate and did not notice an increase in

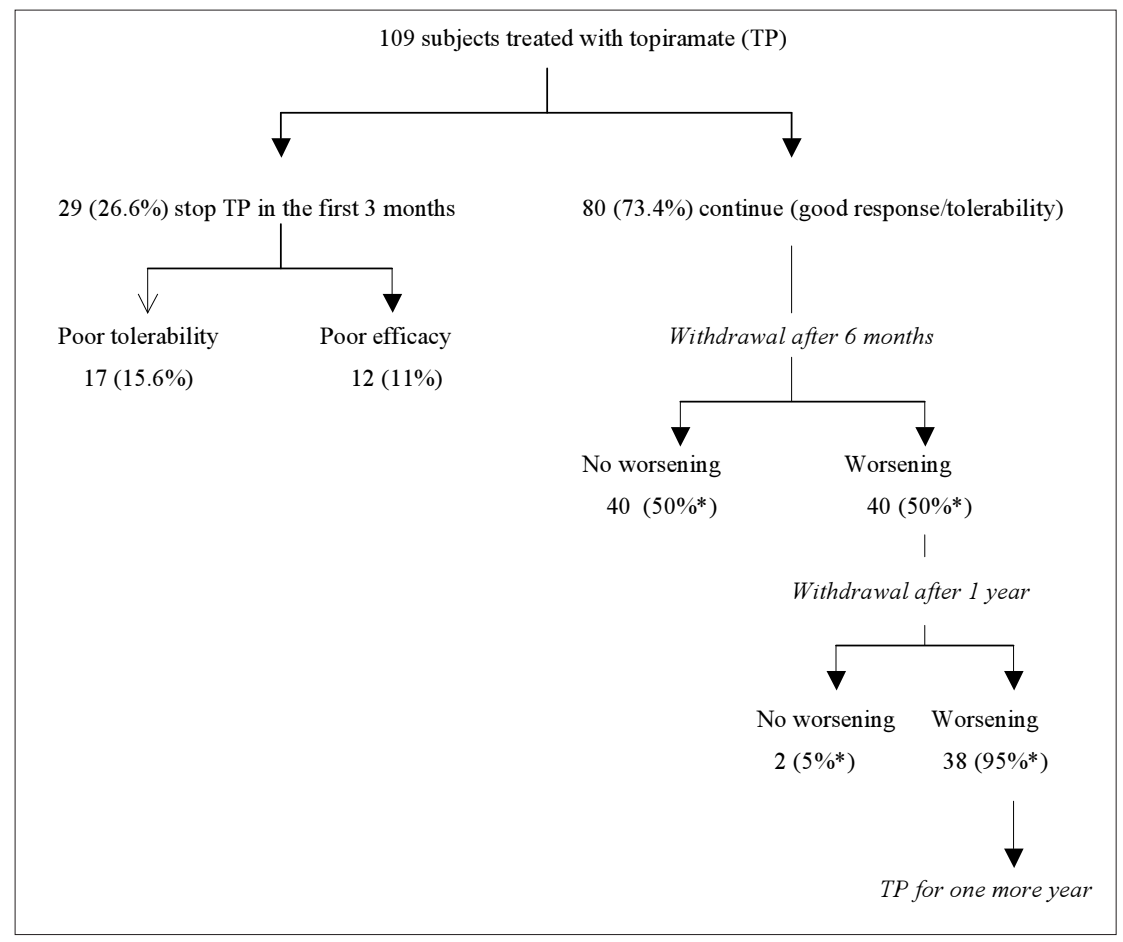

Fig. 1 Summary of results $(* \%$ of those 80 patients who were treated with topiramate for at least 6 months) 
headache frequency after two months. Therefore, 38 (95\%) patients continued on topiramate for more than one year due to an increase in headache frequency after withdrawal.

At the time of writing this manuscript, 10 cases have taken topiramate for between 1 and 2 years, 9 two years, 12 three years, 2 four years and 4 for five years. Five patients have stopped topiramate after more than 2 years. The reasons were: loss of efficacy $(n=1)$, pregnancy $(n=2)$ and renal calculi ( $n=2$ cases, both after 5 years).

\section{Discussion}

The main conclusion of this study is that around half of the patients attending a specialised unit due to frequent migraine headache need preventive treatment for more than one year. From these data it seems clear that current practice recommending periods of preventive treatment of 3-6 months should be reconsidered. This study has several important limitations, which make our conclusions preliminary. First, these results are not applicable to all migraine patients but only to those with frequent or very frequent headache and in a specialised setting. Second, this is an open, exploratory study, even though the conclusions indicate that controlled studies testing prolonged preventive treatment of migraine are not only justified but absolutely necessary. In fact, 40 out of 80 patients worsened immediately after topiramate withdrawal at 6 months. All of them improved after topiramate was reintroduced. Only $2(5 \%)$ of these 40 patients were able to stop preventive treatment after one year, which suggests that most patients whose headache worsens after the usual withdrawal at 6 months actually need preventive treatment for periods longer than one year. That actually hap- pened in many of the patients we could follow for up to 5 years. Maybe for some patients a more careful titration could be done as opposed to a longer period in the same dose; for example, after 6 or 12 months of response, put the patients on half the dose for another 6 months.

Patients with a higher need of prolonged treatment were those with chronic migraine, especially if they overused symptomatic treatments. These chronic migraine patients have been shown to respond satisfactorily to topiramate $[7,8]$, even in the presence of overuse and in controlled conditions $[9,10]$. Interestingly, among the group of responders in long-term treatment there was only one patient whose headaches became worse while on topiramate. Adverse events were similar to those seen in previous clinical trials with topiramate [11-13]. None of these patients discontinued the drug due to unbearable adverse events in the first two years of treatment. Pregnancy and renal colic were the reasons for stopping topiramate after more than two years in a total of four patients. On the other hand, our experience surely reflects the results obtained with topiramate in daily practice in headache clinics when treating migraineurs with frequent headaches: around $15 \%$ of patients do not tolerate the drug (mainly due to cognitive side effects), $10 \%-15 \%$ do not respond, while the remaining $70 \%$ exhibit good (and long-term) efficacy [7, 8].

The ideal duration of preventive treatment for migraine is not known. These results show that half of patients consulting with frequent migraine need prolonged preventive treatment for more than one year and should be taken into account in the clinical practice. This calls for controlled studies testing the pros and cons and investigating the profile of the patients who could obtain benefits from this approach.

Acknowledgements This study was not sponsored.

\section{References}

1. Lipton RB, Scher AI, Kolodner K et al (2002) Migraine in the United States: epidemiology and patterns of health care use. Neurology 58:885-894

2. Silberstein SD (2000) Practice parameter: evidence-based guidelines for migraine headache (an evidence-based review): report of the Quality Standards Subcommittee of the American Academy of Neurology. Neurology 55:754-762
3. Steiner TJ, MacGregor EA, Davies PTG (Writing Committee) (2004) Guidelines for all doctors in the diagnosis and management of migraine and tension-type headache, 2nd Edn (revised August). Available at www.bash.org.uk

4. Tfelt-Hansen P (2006) Prioritizing prophylactic treatment of migraines. In: Olesen J, Goadsby PJ, Ramadan NM, Tfelt-Hansen P, Welch KMA (eds) The headaches, 3rd edn. Lippincott Williams \& Wilkins, Philadelphia pp 567-568
5. Headache Classification Subcommittee of the International Headache Society (2004) The International Classification of Headache Disorders. Cephalalgia 24[Suppl 1]:8-160

6. Headache Classification Committee (2006) New appendix criteria open for a broader concept of chronic migraine. Cephalalgia 26:742-746

7. Pascual J, Sánchez del Río M, Mateos $\mathrm{V}$ et al (2003) Topiramate for patients with refractory migraine: an observational, multicenter study in Spain. Neurología 18:428-432 
8. Peres MFP, Mercante JPP, Tanuri FC, Numes M, Zukerman E (2006) Chronic migraine prevention with topiramate. J Headache Pain 7:185-187

9. Silvestrini M, Bartolini M, Coccia M et al (2003) Topiramate in the treatment of chronic migraine. Cephalalgia $23: 820-824$
10. Diener HC, Goadsby PJ, Bussone G et al (2006) Assessing the efficacy and safety of topiramate for the prevention of chronic migraine. J Headache Pain 7[Suppl 1]:S45-S46

11. Brandes J, Saper JR, Diamond M et al (2004) Topiramate for migraine prevention: a randomized controlled trial. JAMA 291:965-973
12. Diener HC, Tfelt-Hansen P, Dahlof C et al (2004) Topiramate in migraine prophylaxis. Results from a placebocontrolled trial with propranolol as active control. J Neurol 251:943-950

13. Silberstein SD, Neto W, Schmitt JJ, Jacobs D (2004) Topiramate in migraine prevention: results of a large controlled trial. Arch Neurol 61:490-495 